\title{
Impact on integration of Lean Manufacturing and Six Sigma in various applications - a review
}

\author{
G.Muthukumaran $^{1}$, V.S.K.Venkatachalapathy ${ }^{2}$, K.Pajaniradja ${ }^{3}$ \\ ${ }^{I}$ (Department of Mechanical Engineering, Pondicherry Engineering College/ Pondicherry University, India) \\ ${ }^{2}$ (Department of Mechanical Engineering, Sri Manakula Vinayagar Engineering College/ Pondicherry \\ University, India) \\ ${ }_{3}^{3}$ (Department of Mechanical Engineering, Pondicherry Engineering College/ Pondicherry University, India)
}

\begin{abstract}
Lean Manufacturing is a concept of improving the speed and efficiency of an organization by eliminating waste. On the other hand Six Sigma is a continuous improvement plan that is proposed to reduce variability. This paper presents the concept of integrating Lean manufacturing and six sigma, and the approach how the two concepts are merged in industries to increase the product through put and to improve the quality of the product by reducing the process variability. An approach to L $6 \sigma$ is also reviewed along with its Application.
\end{abstract}

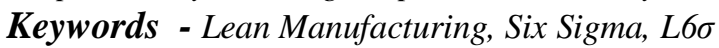

\section{INTRODUCTION}

The Lean Six Sigma (L6\%) is a combination of two methodologies, Lean and Six Sigma that focus on continuous process improvement The Lean approach derives from the Toyota Production System (TPS) which became well-known in the 1980's as Toyota began its growth to supremacy In the US car market by producing less expensive cars with higher quality than their US Manufacturers [1].

The lean approach is planned to improve the speed and efficiency of an organization by eliminating waste. Six Sigma on the other hand, is a continuous improvement plan that is intended to reduce variability. Six Sigma was developed in the 1980 's by Motorola in an effort to improve their quality by reducing variability in their manufacturing operation as they competed in the semiconductor industry [2].

Six Sigma derives from Total Quality Management (TQM). Like its predecessor, Six Sigma relies on the use of statistical analysis and other quality tools to identify and eliminate defects but provides a framework for using them and extends its focus beyond quality to other strategic areas of the organization. Separately, Lean and Six Sigma methodologies often fail to lead to results that achieve the dramatic improvements that organizations desire. Though Six Sigma is adept at identifying and eliminating defects, it does not address how to optimize the system by improving process flow. Lean methodologies, on the other hand, lack the statistical analysis required to achieve a truly "lean" system. By combining the Lean and Six Sigma methodologies, L6 $\sigma$ aims to achieve total customer satisfaction and improved operational effectiveness and efficiency by removing waste and non-value added activities, decreasing defects, decreasing cycle time and increasing first pass yields [3],

The objective of combining the two major techniques is to reduce the cost, irrespective of the product and the industry.

\section{Integrating Lean And Six Sigma:}

The concept of merging LM and $6 \sigma$ can be traced back to 1997 when BAE Systems tried to combine LM principles with $6 \sigma$. The Company named their program Lean Sigma strategy to protect market share in aerospace industry [4]. They mixed together, the Kaizen team with Black Belts planning at reducing variation within their processes. As a result BAE systems achieved substantial improvements in productivity, lead time, savings and reliability. In 1999 an effort to combine LM and $6 \sigma$ was carried out by Maytag Corporation. The corporation basically reengineered one of its production lines making use of the core concepts of LM and $6 \sigma$, by this approach the corporation reduced down manufacturing cost and achieved savings in million dollars [5].

Smith and Adams [6] presented the experience of TBM Consulting Group in implementing Lean Sigma. The company first implemented Lean principles to expose waste and then Six Sigma principles were adopted to reduce variation. The company claimed that over one million dollar savings in scrap and manpower has been achieved annually. Rockwell Automation Power System has combined the structured problem solving and training structure of SS programs with the Lean concepts and Kaizen teams and called the program Power Lean. The approach used value stream mapping and Kaizen events to categorize improvement opportunities while SS problem solving structure and Black Belt leader concept have been used to ease larger improvement opportunities and to implement Lean flow [7]. 
Another case study of using $6 \sigma$ and LM took place in a company that converted paper documents to electronic copies. The company used a modified DMAIC process where the principles of Lean were introduced during every phase of the DMAIC process [8]. The implementation of this process resulted in reduction of error rate, increased productivity and reduced production cost.

Another aerospace company named Northrop Grumman tried to integrate a problem solving tool developed by GE called Workout with Kaizen and Lean Thinking events. The company used also $6 \sigma$ statistical tools to validate solutions and to treat with the harder quality problems [9].

While analyzing the previous efforts in combining LM with $6 \sigma$ conclusions can be reviewed as follows: All these efforts took place in western countries and in large fortune companies, there have been two implementation approaches to combine LM and SS; the first is solving less complex problems using Lean tools then applying SS to harder problems to control variation, and the second is applying DMAIC using some Lean tools in every phase.

Advantages of lean Six Sigma - a comparative table:

\begin{tabular}{|l|c|c|c|}
\hline \multicolumn{1}{|c|}{ ISSUES/PROBLEMS/OBJECTIVES } & $\begin{array}{c}\text { SIX } \\
\text { SIGMA }\end{array}$ & $\begin{array}{c}\text { LEAN } \\
\text { MANUFACTURING }\end{array}$ & $\begin{array}{c}\text { LEAN } \\
\text { SIX } \\
\text { SIGMA }\end{array}$ \\
\hline Focuses on customer value stream & No & Yes & Yes \\
\hline Focuses on creating a visual workplace & No & Yes & Yes \\
\hline Creates standard work sheets & No & Yes & Yes \\
\hline Attacks work-in-process inventory & No & Yes & Yes \\
\hline Focuses on good house keeping & Yes & No & Yes \\
\hline Process control planning and monitoring & Yes & No & Yes \\
\hline $\begin{array}{l}\text { Focuses on reducing variation and achieve } \\
\text { uniform process outputs }\end{array}$ & Yes & No & Yes \\
\hline $\begin{array}{l}\text { Focuses heavily on the application of statistical } \\
\text { tools and techniques }\end{array}$ & yes & Yes \\
\hline $\begin{array}{l}\text { Employs a structured, rigorous and well planned } \\
\text { problem solving methodology }\end{array}$ & No & Yes \\
\hline $\begin{array}{l}\text { Attacks waste due to waiting, over processing, } \\
\text { motion, over production, etc. }\end{array}$ & & \\
\hline
\end{tabular}

\section{VARIOUS APPLICATIONS OF LSS}

Duane K. Allen and Phil Laure [10], in this paper overviewed concepts and tools from each school. And also contains methods and tools from the Training-Within-Industry (TWI) Service training program, which provides a training foundation for present day Lean Six- Sigma process improvement. The many activities that fall in the domain of test can be modeled as processes and thus can benefit from the discipline of process improvement. Process improvement is itself a process that helps organizations bring improved product, more quickly, at a competitive price. The methods of process improvement are themselves developing. Two major schools of process improvement of the 1990's, Six-Sigma and Lean Manufacturing, are merging to a unified methodology to gain the advantages of each school.

Antonio Carlos Tonini et al [11] in this article verified the advantages of using Lean Production practices, based on a Multiple Case Study on some software organizations that uses this methodology. The study shows that the projects were finished more quickly and they presented more effective results. Six Sigma emphasizes the variability causes search. The special causes are more evident, which favors their identification, while the frequent causes are more complicated to be identified and solved and, for that, they request a specialists' participation. Many software development process variability causes are common and it is not always possible to have Six Sigma specialists to identify them. An alternative might be the visibility criteria proposed by Lean Production. Instead of this criterion, software engineers are able to more easily notice the mistakes and their causes than Six Sigma specialists.

M.G Kanakana et al [12] in this work they are proposing to use this process control strategy of Lean Six Sigma and apply it within an academic education. The Engineering education institutions in South Africa are under pressure to increase the throughput rate for undergraduate students, being a developing country with a national throughput rate of 14 percent after 6 years entering the system, the issue is imperial. Although Lean Six Sigma is mainly applied in manufacturing sectors, there is evidence that this methodology can be applied successfully to any process. In other words apply a break through strategy to affect faculty objectives in academia so as to improve the throughput rate and to increase faculty revenue. 
Aicha Aguezzoul and Aimé Nyoungue [13] in this paper presented an application of LSS approach in the hospital sector by focusing on the need to implement this tool to improve the value chain of healthcare, and the KPIs used. Nowadays, the provisions of healthcare are selected for their quality. Hospitals have begun intensely to use one of concept of ISO 9001: "The customer voice", which consists on using the perception of patients to organize their services and improve their global performance. The implementation of Lean Six Sigma (LSS) approach helps to achieve this goal. This approach corresponds to the merger of two quality improvement: Lean and Six Sigma. Both methods encompass a number of principles and tools designed to increase process efficiency by reducing wasteful steps.

Majed Alsmadi and Zulfiqar Khan [14] in this paper developed an integrative Lean Sigma framework for SMEs based on research gaps and actual requirements, the outline was formulated using a triangulation methodology consisting of literature review, Delphi survey and structured interviews. In order to improve and sustain competitive advantage, organisations across the world have embraced different tools and techniques that they hope will keep them alive within the cutthroat market place. Currently, Lean Management LM and Six Sigma SS are the most widely recognised continuous improvement CI initiatives accessible by organisations with faddish characteristics. At the same time they are considered a subject of a growth body of literature which lacks consensus regarding their origins and their association with their predecessor that is the TQM philosophy. This paper introduces evidence which proposes that LM and $6 \sigma$ are not dizzying array of management fads rather the normal extension of TQM as evolved from the theories of Adam Smith.

Dietrich Eberts et al [15] their approach is to validate by a case study in a wafertest environment and enables establishing the Virtual Time based Flow Principle. Manufacturing organization in the manner of flow production is one of the best solutions to achieve short cycle times, low inventories and a high delivery reliability, which are vital for commercial success. Variability within all production, support and organizational processes is one of the main detractors for establishing a continuous material flow in semiconductor manufacturing. In this contribution an approach for identification, classification, observation, reduction, mastering and even elimination of variability is shown. This is done by combining elements as well as tools of lean manufacturing and Six Sigma.

Dr. Joyce A. Thompsen [16] in this article included an overview of the research results, practical tools and techniques, as well as insights gained from the ongoing site activities and evaluation. Specific implications for other organizations undertaking Lean 6s and Six Sigma initiatives.

A United States military organization is continually seeking to provide the highest quality of equipment at the right time and most cost-efficient manner to the soldiers in combat. Command-level decisions had been taken to vigilantly pursue a combination of Lean 6s and Six Sigma process improvement initiatives throughout the U.S. Tank-automotive and Armaments Command (TACOM). Results were mixed. This researcher was asked to conduct a series of inquiries and studies to determine how to consistently improve and sustain those results. This article summarizes insights from a combination of workforce surveys, studies of the Lean $6 \mathrm{~s}$ and Six Sigma initiatives, and observations and practical application of leadership competencies such as teamwork, collaboration, change management, complex problem solving, and process management.

Xue Wang et al [17] , as a fusion of lean efficiency engineering and six sigma quality control, Lean Six Sigma can be applied to quality management of equipment maintenance, to improve the deficiencies and inefficiency in equipment maintenance process. Regarding the state of the equipment maintenance process, the paper researches the Lean Six Sigma implementation in quality management of equipment maintenance, which can reduce waste and variation in the equipment maintenance process, thereby improving the efficiency and quality of equipment maintenance to ensure the task accomplishment of campaign.

\section{CONCLUSION}

The review briefs about the integration of two concepts, Lean manufacturing and Six Sigma in industries, has a dramatic change in the industry process and quality of the product produced. This is also denoted as Lean Six Sigma (L6\%). This L6 $\sigma$ can be implemented to any kind of industry, for better performance, L $6 \sigma$ is a continuous improvement tool for betterment.

\section{REFERENCES}

[1] Duane K. Allen and Phil Laure,” Exploiting Lean Six-Sigma Quality Tools to improve Test and other processes”, 1-4244-0052-X/06, 2006 IEEE

[2] Antonio Carlos Tonini et al," An Application of Six Sigma with Lean Production Practices for Identifying Common Causes of Software Process Variability", PICMET 2007 Proceedings, 5-9 August, Portland, Oregon 2007 PICMET , Pg: 2482 - 2490

[3] M.G Kanakana et al," Lean Six Sigma Framework to Improve Throughput rate", 978-1-4244-6484-5/10, 2010 IEEE

[4] J. Sheridan[1] J. Sheridan, Aircraft-Controls Firm Combines Strategies Improve Speed, Flexibility and Quality, Gale Group, Penton Media, Inc. 2000.

[5] Dubai Quality Group. The Birth of Lean Sigma, The Manage Mentor, Dubai. 2003.

[6] B. Smith and A. Adams, LeanSigma SM: Advanced Quality, ASQ’s 55th Annual Quality Congress Proceedings, 2001. 
[7] J. Illing, Seamless Integration of Lean Enterprises and Six Sigma. Automotive Manufacturing and Production, Vol.113, No.2,p 66, 2001.

[8] N. Goyal, Applying Lean Manufacturing to Six Sigma - A Case Study, ISixSigma website, Six Sigma Article Spotlights www.isixsigma.com, 2002.

[9] J. McIlroy and D. Silverstein, Six Sigma Deployment in One Aerospace Company, Six Sigma Forum website www.sixsigmaforum.com, 2002

[10] Duane K. Allen and Phil Laure,” Exploiting Lean Six-Sigma Quality Tools to improve Test and other processes”, 1-4244-0052-X/06, 2006 IEEE

[11] Antonio Carlos Tonini et al," An Application of Six Sigma with Lean Production Practices for Identifying Common Causes of Software Process Variability", PICMET 2007 Proceedings, 5-9 August, Portland, Oregon 2007 PICMET , Pg: 2482 - 2490

[12] M.G Kanakana et al," Lean Six Sigma Framework to Improve Throughput rate", 978-1-4244-6484-5/10, 2010 IEEE

[13] Aicha Aguezzoul and Aimé Nyoungue," A preliminary analysis on Lean Six Sigma application in healthcare", 978-1-4577-20253/12, 2012 IEEE.

[14] Majed Alsmadi and Zulfiqar Khan," Lean Sigma: The New Wave of Business Excellence, Literature Review and a Framework".

[15] Dietrich Eberts et al "Managing Variability within Wafertest Production by Combining Lean and Six Sigma", 978-1-4673-03514/12, 2012 IEEE

[16] Dr. Joyce A. Thompsen ," Gaining Greater Benefit from Lean Six Sigma and Leadership Initiatives Within the Military", 0-78039139-X/05, 2005 IEEE.

[17] Xue Wang et al," Lean Six Sigma Implementation in Equipment Maintenance Process", 978-1-4673-0788-8/12, 2012 IEEE 